\title{
Atypical presentation of Goldenher syndrome- a rare scenario
}

\author{
Lath C, Sen S, Mondal M. Maiti D, Singh R, Bose R \\ ${ }^{1,6}$ Resident, ${ }^{3} \mathrm{RMO}$ cum Clinical Tutor, Department of Pediatrics, ${ }^{2} \mathrm{RMO}$ Cum Clinical Tutor, \\ ${ }^{5}$ Resident,Department of ENT, ${ }^{4}$ RMO Cum Clinical Tutor, Dept of Gynaecology and Obstetrics, NRSMCH, \\ Kolkata
}

\section{ABSTRACT}

In 1952 Goldenher described a case with triad of pre auricular tags, mandibular hypoplasia and ocular (epibulbar) dermoid and described the case as Goldenger Syndrome. Exact etiology of this disease is not known. Here we present a case of Goldenher syndrome in a 5 days old newborn who presented with all the classical features except ocular involvement.

Gorlin et.al named this syndrome as oculoauriculovertebral dysplasia due to presence of additional vertebral anomalies ${ }^{2}$ Exact etiology of this disease is not known. Most of the cases are sporadic, though autosomal recessive, autosomal dominant and multifactorial inheritance has also been suggested. ${ }^{2}$ Chromosomal analysis shows no abnormalities. ${ }^{3}$ In this report we presented a case of Goldenger Syndrome in a 5 days old newborn who presented with all the classical features except occular involvement.

\section{Keywords: Goldenher syndrome, preauricular tag and sinus, mandibular hypoplasia, vertebral} anomalies, facial asymmetry, rib anomaly, absent radius.

\section{INTRODUCTION}

Goldenher syndrome is a rare disorder with a incidence rate of 1 per 5800 life birth with male:female ratio $3: 2 .{ }^{1}$ It is presumed to be an inherited condition causing morphological abnormalities of the part developed from the first and second branchial arch during blastogenesis. ${ }^{1}$ Goldenher first described the case in 1952 as a disease that present as a combination of several anomalies such as dermal epibulbar tumors, periauriclar appendices and malformation of ears. Gorlin et.al named this syndrome as

Correspondence: Dr Shubhrakanti Sen

email-sen.shubhrakanti@gmail.com oculoauriculovertebral dysplasia due to presence of additional vertebral anomalies ${ }^{2}$ Exact etiology of this disease is not known. Most of the cases are sporadic, though autosomal recessive, autosomal dominant and multifactorial inheritance has also been suggested. ${ }^{2}$ Chromosomal analysis shows no abnormalities. ${ }^{3}$ Some association recorded in the literature are macrostomia, micrognathia, high arched cleft palate, bifid tongue, malocclution and other dental anomalies. ${ }^{4}$ Some author also pointed out facial muscle hypoplasia, vertebral anomalies, eye anomalies, ${ }^{1}$ disorders of central nervous system, visceral anomalies, ${ }^{5}$ cardiovascular ${ }^{6} \&$ genitourinary abnormalities. ${ }^{7}$ 
Journal of College of Medical Sciences-Nepal, 2013, Vol-9, No-4,

The presences of anomalies of the ear and of limbs are necessary for the diagnosis of this syndrome. In this article we are presenting a case of 5 day old neonate diagnosed as a case of Goldenher syndrome.

\section{CASE HISTORY}

A single, preterm baby (gestational age 36 weeks, male, LSCS, Birth weight- $2.5 \mathrm{Kg}$ ), cried immediately after birth, admitted in our institution on day 5 of life with multiple congenital anomalies.

\section{ANTENATAL HISTORY}

The mother was 26 years old, primigravida, apparently in good health, without a prior history of any major illness. Mother had a history of intake of some oral abortificiant during first trimester as per advised by medical practitioner (no docments available).But as the abortion did not occur, mother continued the pregnancy. Otherwise the antenatal period was uneventful. She had regular antenatal checkups, taken iron \& folic acid tablets regularly. Ultrasonography done on 23 weeks of gestation which revealed major congenital anomalies. She had no history of any fever, rash, lymphadenopathy, radiaton exposure or any exposure to cat during the antenatal period. Mother was a non smoker \& non alchoholic.

\section{INTRANATAL HISTORY}

It was a preterm institutional delivery by LSCS due to premature rupture of membrane \& baby cried immediately after birth without any assistance.

\section{IMMEDIATE POSTNATAL PERIOD}

Uneventful. Baby put to mothers breast within 1 hour of birth, sucking normally from mothers breast. There was no history of any jaundice, convulsion or feeding difficulty.

Baby admitted in our hospital on day 5 of life due to presence of multiple congenital anomalies.

\section{HEAD TO FOOT EXAMINATION}

Head Circumference- $33 \mathrm{~cm}$, anterior fontanelsnormal CC-29cm, Length- $45 \mathrm{~cm}$,

Weight

EAR

ORAL CAVITY

FACE-

NECK-

EYE -

HAND-

CHEST-

ABDOMEN-

GENITALIA-

LOWER LIMB
$-2.26 \mathrm{~kg}$ on day 5 of life.

-Right ear-preauricular tag, sinus \& pit; Left ear-normal -tongue tie, bifid tongue, right sided deviation of angle of mouth, with bifurcation of lip at right angle of mouth.

micrognathia.

short neck.

no obvious anomaly seen.

right hand deformed with short forearm, hypoplastic right thumb, radial deviation of wrist joint, flexon of elbow joint.

\section{norml}

normal

normal male genitalia.

- no obvious visible deformity

SPINE \& CRANIUM - no obvious deformity.

\section{GENERAL AND SYSTEMIC EXAMINATION}

Vitals -HR-110/min, RR-34/min.

No pallor, cyanosis, jaundice, clubbing or oedema.

CVS - S1 \& S2 audible, no murmur.

RESP-bilateral vesicular breath sound, no adventitious sound audible, no intercostal or subcostal retraction.

GI -abdomen is soft, no organomegally, and intestinal peristaltic sound-present.

Modified Ballard Scoring-score

-32; approximately gestational age37 weeks. 
Atypical Presentation of Goldenher Syndrome- a rare scenario

\section{INVESTIGATIONS}

Complete blood count Hb-16.4gm\%, TLC-11300

(N49,L35,M10,E2,B4),

Platelet-3.4lakh,MCV-111.7,MCH-17.2,RDW-

17.2,Reticulocyte count-1\%.

Echocardiography-Small PDA with left to right shunt,osteum secondum type ASD.

Ultrasonography -no visceral or cerebral abnormality, hypoplasia of right parotid gland \& irregularity in right half of mandible seen.

Chest X-Ray- rib abnormality.

Hypoplastic right half of mandible, absent of radius in right forearm. There is also deformity present in the cervical vertebra.

\section{DISCUSSION}

The above findings of the baby clinches us to the diagnosis of Goldenher syndrome.though the physical findings of the baby have some similarities with Teachercollins syndrome, it has now considered to be a different entity, with features most commonly affecting bilaterally and having no aural or ocular abnormality. ${ }^{8}$

The abnormalities are fond to be unilateral in $85 \%$ of cases and bilateral in about $10-33 \%$ cases. ${ }^{9}$ In asymmetric involvement with right side more affected than left side. ${ }^{10}$ our reported case has similar involvements. The reported frequency of cardiovascular abnormality ranging from 5$58 \%$.Our case also had cardiac lesion in the form of ASD. There are some association found between maternal intake of some drugs like retinoic acid, thalidomide etc., with development of Goldenher syndrome. ${ }^{11}$ In this case also there was some history of maternal drug intake though no documents were available. In Goldenher's syndrome ocular anomalies specially bilateral dermoid present in $60 \%$ of cases and vertebral and ear abnormalities are present in $40 \%$ cases. $^{12}$
The characteristic vertebral, ear, cardiac, facial, rib, mandibular anomalies all were present in our case. but surprisingly we didn't found any ocular abnormalities, which is reported in maximum cases in literature.

\section{CONCLUSION}

Goldenher syndrome can also be presented without any ocular anomaly as seen in our case.

\section{REFERENCES}

1. Reddy MV,Reddy PP,Usha Rani P,Hema Bindu L.Facio-auricular vertebral syndrome-a case report.Indian J Hum Genet 2005;11:156-8.

2. Nakajima H, Goto G, Tanaka N,Ashiya H, Ibukiyama C.Goldenher syndrome associated with various cardiovascular malformations.Jpn Circ J 1998;62:617-20.

3. Rao VA,Kaliaperumal S, Subramanyan T, Rao KR, Bhargavan R. Goldenhar's sequence with associated juvenile glaucoma in Turner's syndrome.Indian J Ophtjhalmol 2005;53:2678.

4. Pinheiro AL, Araujo LC, Oliveira SP, Sampaio MC, Freitas AC. Goldenhar's syndrome-case report. Braz Dent J 2003;14:67-70

5. Lessick M, Vasa R, Israel J. Severe manifestations of oculo auriculo vertebral spectrum in a cocaine-exposed infant.J Med Gen 1991;28:803-4.

6. Morrison PJ,Mulholland HC, Craig BG,Nevin C. Cardio vascular abnormalies in oculoauriculo-vertebral spectrum (Goldenhar Syndrome).Am J Med Genet 1992;44:425-8.

7. Ritchy ML, Norbeck J,Huang C, Keating MA, Bloom DA.Urologic manifestation of Goldenhar syndrome.Urology 1994;43:88-91. 
Journal of College of Medical Sciences-Nepal, 2013, Vol-9, No-4,

8. Mehta B,Nayak S.Goldenhar syndrome with unusual features:A case report.Indian J Dermatol Venereal Leprol 2008;74:254-6.

9. Sharma JK, Pippal SK, Raghuvanshi SK, Shitij A. Goldenhar-Gorlin's syndrome:A Case report.Indian J otolaryngol Head Neck Surg 2006;58:97-101.

10.Rao VA,Rao S.Lamba PA. Goldenhar's syndrome.Indian J of Opthamol 1982;30:1479.
11.R Kapur,R kapur, S Sheikh, s Jindal,S Kulkarni.Hemifacial microsomia:A case report.J Indian Soc Pedod Prevent Dent 2008;26:34-40.

12.Klkarni VV, Shah MD,Parikh AA. Goldenhar syndrome: A case report. J Postgrad Med 1985;31:177-9. 